Revista Iberoamericana, Vol. LXIX, Núm. 204, Julio-Septiembre 2003, 565-573

\title{
CONTRA EL ATARDECER
}

\author{
POR \\ Rick McCallister \\ Delaware State University
}

La poesía de Pablo Antonio Cuadra (1912-2002) está arraigada en el nacionalismo tanto como en la valoración al héroe. Para Cuadra, la patria es un conjunto de seres anónimos de los que, de vez en cuando, unos cuantos saltan a la historia por sus hechos particulares. Estos sirven de modelo para las masas y en cierto sentido, de patrón histórico para la nación. Con sus acciones ofrecen liderazgo y esperanza al pueblo común. En este sentido, Cuadra sigue la idea de José Ortega y Gasset en la que proclama héroe a aquel que quiere ser él mismo, y que se redime del anonimato por su valor propio (Balladares, "El tiempo...” 164). Es una actitud romántica; épica en vez de histórica, fundada más en la mitología que en la crónica (Jameson, The Ideologies... I: 158; ver también a Hayden White). Por prestarse a la sustitución de significantes a lo largo del eje metafórico, la poesía de Cuadra postula una exégesis alegórica. Encuentra su base narrativa en las raíces de la cultura nicaragüense y en los héroes de culturas madres, ligando los dos con las realidades actuales y con la profecía a través de la circularidad del tiempo. Sigue la temporalidad maya del Chilam Balam de Chumayel, en la cual los sucesos de cada época o katún se repiten en una futura época. Por medio de estos ciclos, el poeta predice la liberación y la grandeza para la patria.

Cuadra empieza como poeta neopopular dentro del movimiento vanguardista con su llamada "poesía guitárrica” que evocaba un campo edénico con sus ritmos campestres y sus temas bucólicos. Sin embargo, se trata de una expresión superficial, dado que Cuadra, como miembro de la oligarquía, era ajeno a las experiencias de los campesinos que aparecen en su obra. Como los vanguardistas europeos, Cuadra y sus contemporáneos nicaragüenses atacaron la condición del arte burgués como algo divorciado de la vida cotidiana (Bürger 239). El arte que no se diferencia de la praxis de la vida, sin embargo, pierde su capacidad crítica tanto como su distancia artística -la praxis se convierte en la estética, el arte en práctica. El propósito de dar una función social al arte reintegrado en la praxis cotidiana crea una contradicción entre la ideología populista y la praxis arbitraria de seleccionar entre formas populares por los vanguardistas -algo que reafirma la creación individual (Bürger 240-1). Por el otro lado, el uso de manifiestos o recetas-ars poeticaey la disciplina de los grupos vanguardistas atacan la creatividad del artista (Bürger 242). De todos modos, el vanguardismo nicaragüense nunca pudo romper la autonomía tradicional entre la vida cotidiana y el arte. Mientras quiso subvertir la separación artificial 
entre la alta cultura y la vida, acudió a las ideas de T. S. Eliot y José Ortega y Gasset de salvar el arte contra la modernización y la cultura de masas. El resultado fue más bien nostalgia que “cultura popular” (Huyssen 221-3).

La vuelta hacia la tradición tuvo que ver con el desengaño que sentía la generación de Cuadra hacia la dominación de los Estados Unidos, que llegó a favorecer a los liberales (Ramírez 286-7). La modernidad en Hispanoamérica nunca llegó a ser mucho más que una teoría entre la élite intelectual. Con la hegemonía norteamericana y europea, fue vista por un espejo de dominación. Para la mayoría representaba la importación de cachivaches modernos y la exportación de capital a Europa y los Estados Unidos (Quijano 145-6). Ya que la promesa libertaria de la modernidad fue subordinada a las necesidades del poder, sólo el poder quedó como alternativa, dejando una oligarquía criolla en vez de una burguesía auténtica (Quijano 149-50). Aquí es preciso tener en cuenta que Jürgen Habermas proclama que Friedrich Nietzsche señala el fin de la dialéctica de la ilustración como fuerza libertadora (Habermas 53). Con el rechazo del dominio estadounidense, el movimiento de vanguardia adoptó actitudes anti-burguesas e irracionales, buscando la salvación cultural en el pasado con el lema patriarcal, "Estamos contra nuestros padres y con nuestros abuelos” (Ramírez 286-7). A pesar de que Aníbal Quijano opina que en Hispanoamérica coexisten muchas etapas históricas y que la historia no es una metanarrativa lineal y unidireccional, que el pasado que corre al lado del presente no es nostálgico ni edénico sino una experiencia personal del pasado que imparte sabiduría (Quijano 150), no se ve esta visión histórica, sin embargo, en la obra de Cuadra.

De acuerdo con su mirada hacia el pasado, Cuadra utiliza el tiempo mitológico, el que funciona como diálogo vertical entre los mundos físico y metafísico. Glorifica el pasado como una tierra prometida eterna fuera del tiempo y por encima del mundo presente material. En este sentido, el pasado funciona más como espacio que tiempo. Percibe el presente como una época degenerada de mentiras, trampas y robos. Percibe el futuro como el fin del tiempo, un mero punto de mediación relativamente próximo en el que el mundo volverá a un edén (Bakhtin 147-8). La sociedad se caracteriza por una profunda contradicción entre ideología y praxis, una polaridad extrema a través del eje de demencia y, por tanto, el sistema está en peligro de derrumbarse.

eje de la demencia

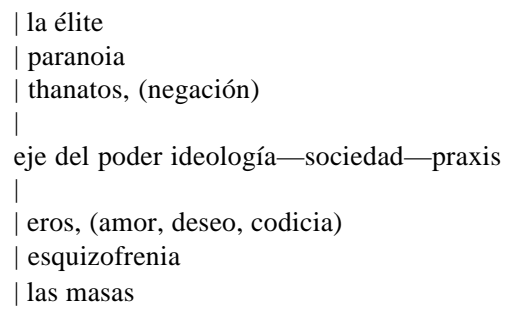


1. Visión social deleuziano (Anti-Oedipus y Nomadology)

pasado $>>>$ presente $>>>$ futuro

2. Visión moderna lineal del tiempo.

pasado

futuro (punto de mediación entre el pasado y el presente)

presente

3. Visión épica o medieval del tiempo.

La estructura paradigmática del tiempo mitológico hace reconocible al incomprensible. En una estetización de la política, la vanguardia reduce la actividad política a una forma ritual (Docherty 18). Traduce las tradiciones, ofreciendo una metanarrativa en términos de un código amaestrador (Docherty 11). El apoderamiento del tiempo a través de profetizar los ciclos mitológicos convierte al poeta en hieros. Según Martin Heidegger “el poeta proclamó lo santo, el que se revela al pensador. La poesía y el pensamiento son, por supuesto, independientes, pero, al final es la poesía que resalta del pensamiento en sus etapas iniciales" (Habermas 55). Como el tlatoani azteca o el chilam maya, asocia el poder con la maestría de la lengua -en este caso el huehuetlatolli o lengua de Zuyua "habla de los ancianos”, centrado en el pasado (Todorov, The Conquest... 78-9).

Mircea Eliade (1971: ix) vio la tradición oral como una "rebelión contra el tiempo histórico”, “un rechazo del tiempo lineal profano”. La mitología tiene la tendencia de ignorar las raíces de los sucesos humanos a favor de una interpretación paradigmática (Bricker 3). Como notó Claude Lévi-Strauss, la mitología es bricolaje -un arreglo alternativo de los restos y deshechos de los sucesos históricos (Bricker 4). Enfatiza la estructura más que la individualización, los papeles de héroe y villano son intercambiables (Bricker 8). Por tanto, corre el riesgo de degenerarse en pastiche, una parodia e imitación de estilos muertos, un canibalismo del pasado en el que lo contemporáneo se disuelve en simulacro (Docherty 76).

La poesía mito-histórica de Cuadra funciona como las obras “enciclopédicas” medievales como La divina comedia, el tiempo está sujeto a la interpretación simbólica. Todo lo espacial y temporal, las imágenes de personas y objetos, tanto como sus acciones, tiene un significado alegórico o simbólico (Bakhtin 156, Docherty 16). Por interpretar textos y signos, Cuadra, como los sacerdotes medievales, tanto como los mayas, opera a través de la afiliación en vez de la filiación (Tedlock 23). La repetición de ciclos con una mezcla del pasado y el futuro hace posible una profecía arraigada en la memoria (Todorov, The Conquest... 85).

Con su primer libro, Poemas nicaragüenses (2 eds., 1934, 35), Cuadra asimila el habla campestre a formas vanguardistas para crear una geografía nacional de tendencia vernácula. Un poema clave, “Introducción a la tierra prometida,” elabora una visión mítica de su patria que liga el paisaje, las costumbres, la flora y la fauna, todos denominados en forma adánica, usando una voz popular (Arellano 350-1). Ya libre de la imitación de 
formas y motivos populares, Cuadra empieza a conocer a su pueblo, a delimitar su espacio, y a defenderlo contra el invasor.

A través del uso de la repetición histórica y la alegoría como bases de actividades oraculares, consiguió la unión del mito y la alegoría; universalizó eventos particulares, dejando implícitas las comparaciones de sucesos paralelos en las historias o mitologías de los grupos que conformaban el patrimonio etno-cultural nicaragüense. Se distinguió de Pablo Neruda y Ernesto Cardenal en que su narrativa era más pluridimensional, con menos énfasis en la historia “objetiva”. En su búsqueda de alegorías arraigadas en la cultura nacional, su poesía reflejaba influencias de La estación violenta de Paz.

Siete árboles contra el atardecer (1980) es una taxonomía cultural de Nicaragua en su momento de cataclismo, en medio de la revolución contra un tirano que prefería destruir la patria antes de abandonar el poder. De acuerdo con su fuente, Siete contra Tebas, por Esquilo, es una obra catártica que busca fin al ciclo de la violencia. Como los combatientes griegos, cada uno con su patrón divino pintado en el escudo, cada árbol cuenta su historia cultural ejemplar o sea al novel personal, familiar o nacional.

En su papel de poeta y hieros, Cuadra llama a las fuerzas de la naturaleza para auxiliar a su patria en su época de crisis, como había hecho años antes en su "Poema del momento extranjero en la selva”, de Poemas nicaragüenses. Con esta llamada, Cuadra implica que se han agotado todos los medios racionales, sólo quedan la cultura y la naturaleza. Cuadra es muy minucioso en su selección, ya que la tragedia de Tebas fue prolongada por sustituir a Afrodita (el amor) con Furia (el odio) en el escudo, lo cual eliminó cualquier posibilidad de resolución pacífica. De esta manera, Cuadra quería enfatizar las funciones humanitarias de cada protector en este esfuerzo por parar el ciclo de violencia. Cuadra agrega más dimensión a los héroes por establecerles una alcurnia en forma de taxonomías particulares. Explica los detalles botánicos de cada árbol, sus propiedades físicas: su tamaño, forma, hojas, frutas, ubicación -tanto como su fortaleza- sus usos comerciales y culturales, su descubrimiento y su simbolismo local.

De cierta manera, sin embargo, la historia de los hermanos Etéocles y Polínice refleja la desintegración del sistema cupiacumi en Nicaragua cuando Somoza convirtió su dominio en nomadología después del terremoto de 1972 al botar a sus socios menores, los conservadores (Ramírez 137-9). Antes, los liberales y conservadores repartían puestos domésticos y diplomáticos, compartían intereses económicos y financieros, y utilizaban la Guardia Nacional para protegerse contra los trabajadores y campesinos (Ramírez 1278). Con la tiranía de Etéocles, Polínice sólo tiene recurso a la violencia.

El poema clave del libro es “El Jícaro”, que se trata de Crescentia cujete et al., un árbol pequeño de hoja perenne que da una fruta redonda u oval que se ahueca para utilizarla en forma de taza o pichel. La forma costeña tiene hojas en forma de cruz (Cuadra Downing 286-7).

Su fruto es el guacal o la jícara

-la copa de las bebidas-

que el campesino adorna con pájaros incisos

-porque bebemos el canto- 
$\mathrm{Su}$ fruto suena en nuestras fiestas en las maracas y las sonajas -porque bebemos la música

La forma de las hojas y su uso de cáliz obviamente le da un fuerte significado religioso, no sólo entre los cristianos sino también entre los indios centroamericanos. Se ve esto en el Popol Vuh, cuando Xquic recibe el cuerpo de Hun Hunahpú a través de la comunión con el Jícaro.

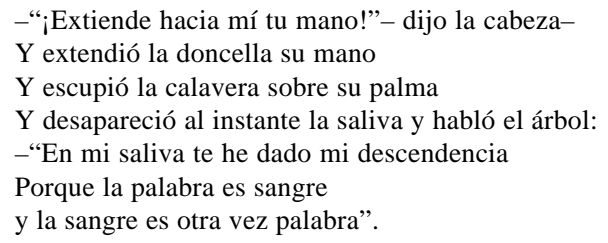

El verso incorpora el paralelismo común a la Biblia y la poesía maya para contar el nacimiento milagroso del Popol Vuh, cuando el héroe sacrificado Hun-Hunahpú renace gracias a Xquic, cuyo nombre significa “sangre” (o más bien “sangrita” o “sangre mujer”) agregando al juego de palabras. Xquic dio a luz a los gemelos Hunahpú y Xbalanqué, que por fin derrotaron a los señores de Xibalbá. Con su traición a la muerte, Xquic hizo posible la victoria del tiempo y la vida.

El pecado de Hun-Hunahpú y su hermano Vucubó-Hunahpú fue haber molestado a los señores de Xibalbá con el ruido de su juego. Por eso tuvieron que jugar en una competencia arreglada.

\author{
... contra los poderes de la Casa Negra \\ ... contra los señores de la Casa de los Murciélagos \\ Contra los señores de la Casa Oscura \\ - Quemama ha \\ en cuyo interior sólo se piensan siniestros pensamientos. \\ "Seréis destruido, seréis despedazado \\ y aquí quedará oculta vuestra memoria" \\ dijeron los señores de la Casa de las Obsidianas \\ (el cuartel- la Casa de las Armas) \\ Y decapitaron al libertador.
}

El mártir libertador se compara a Pedro Joaquín Chamorro, cuyo asesinato por los somocistas precipitó la última etapa de la revolución sandinista. Cuadra dicta la taxonomía y significado cultural del árbol objetiva y tranquilamente, sólo al fin acecha al lector con el epígrafe: "En memoria de Pedro Joaquín Chamorro / cuya sangre preñó a Nicaragua la libertad”. Somoza, entonces, es Vucub Camé, el señor de Xibalbá, cuyas mansiones: “la Casa Negra”, "la casa de los Murciélagos”, "la Casa Oscura / -quemama ha-”, "la Casa de las Obsidianas / (el cuartel -la Casa de las Armas)”, y “La Casa de las Tineblas / (los que censuran)" representen las fuerzas bajo su dominio. A pesar de toda su fuerza, Somoza es impotente contra el movimiento generado por la muerte de Chamorro. 


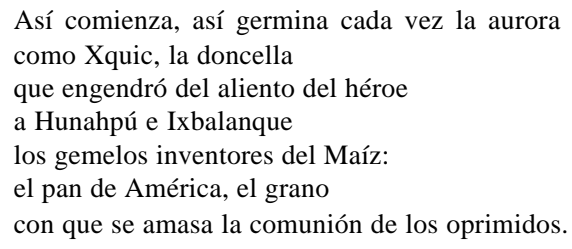

Con el sacrificio de Hun-Hunahpú/Chamorro, Xibalbá será derrotado. Sólo a los que les ha llegado su tiempo irán a la muerte. Con la alternación de vida, muerte y vida, empieza el tiempo y pronto amanecerá el primer sol (Tedlock 51).
Niveles de texto
A. nivel literal
B. nivel alegórico
C. nivel moral
D. nivel anagógico

Exégesis

Sacrificio y resurrección de los hermanos Hunahpú

Lucha entre tiranía y la democracia

Martirio de Pedro Joaquín Chamorro

Promesa del triunfo de la revolución

4. Niveles de exégesis en "El jícaro"

Los árboles de Siete árboles contra el atardecer ofrecieron la última línea de defensa contra los que preferían dejar la patria en escombros antes de entregar el poder al pueblo. De cierta manera, se puede decir que la obra refleja la lección de Las mil y una noches, "narrar o morir" (Todorov, The Conquest... 78). La cultura y la naturaleza son más duraderas que los monumentos de metal o cemento y, por tanto, forman el verdadero núcleo de la patria.

El ur-texto que ofrecen los árboles liga a Nicaragua no solamente con sus raíces directas sino también con las civilizaciones clásicas de la India y China. En este sentido, da una geografía que saca la nación de su aislamiento e ignorancia con modelos culturales clásicos para el futuro. Las dendrocronologías funcionan a varios niveles. Dentro del texto, las descripciones e historias de cada árbol da un nivel literal de exégesis. El nivel alegórico consiste en los valores culturales y su papel en vencer las fuerzas del mal. El nivel moral se concentra en el papel del poeta en la recreación y la re-fundación de elementos culturales contra la tiranía. El elemento anagógico representa el progreso de la revolución tanto como el de Nicaragua y su pueblo (Jameson 152).

Cada fase de la poesía de Cuadra es una época de descubrimiento y recreación. Su primera poesía es un descubrimiento de la patria y su folclor. Su poesía religiosa es más bien un descubrimiento de sí mismo y el desarrollo de su enfoque individualista. Su poesía mito-histórica combina esas actitudes para establecer una nueva mitología basada en el heroísmo. Inspira a los héroes corrientes y futuros por ligarlos a los campeones precolombinos y las raíces clásicas de Nicaragua. Empezando con El jaguar y la luna, hay 
una trayectoria hacia lo universal-en aquel libro, los héroes eran mesoamericanos. En Cantos de Cifar, eran mediterráneos o indios nicaragüenses. Finalmente, en Siete árboles contra el atardecer, Cuadra teje su mitología de las raíces culturales del mundo entero.

En la obra de Cuadra existen las dos tendencias conservadoras denominadas por Habermas. Su primera obra corresponde muchas veces al neo-conservadurismo con las ganas de poder y soberanía, la fuerza dionísiaca de la poética, el uso de actitudes de la modernidad para apartarse del mundo moderno hacia mundos antiguos y lejanos, y la utilización de yuxtaposiciones maniqueístas. Su obra posterior, por ver la decadencia de la modernidad como prueba de su fracaso, y por retirarse a la premodernidad y la ética cosmológica, muestra correspondencias con el paleo-conservadurismo (Habermas 107). Lo que ambas tendencias tienen en común con Cuadra es su fidelidad al tiempo cíclico y el rechazo del atardecer que lleva hacia el tiempo lineal.

BiBliografíA

Arellano, Jorge Eduardo. Panorama de la literatura nicaragüense, 4th ed. Managua: Nueva Nicaragua,1982.

"El movimiento nicaragüense de vanguardia”. Tesis doctoral: Universidad Complutense (Madrid) December 1985.

Auerbach, Erich. Mimesis. Garden City, NY: Anchor, 1957.

Bakhtin, Mikhail Mikhailovich. The Dialogic Imagination. Austin: University of Texas Press, 1981.

Balladares, José Emilio. “El tiempo mítico y el tiempo del hombre en los Cantos de Cifar”. Revista del Pensamiento Centroamericano 177/X-XII (1982): 164. La palabra y el tiempo. San José: Libro Libre, 1986.

Baudrillard, Jean. "The Evil Demon of Images and the Procession of Simulacra". Postmodernism. Thomas Docherty, ed. New York: Columbia, 1993. 197-205.

Beverley, John \& Marc Zimerman. Literature and Politics in the Central American Revolutions. Austin: University of Texas Press, 1990.

Bourdieu, Pierre. Ce que veut dire parler: L'économie des échanges linguistiques. Paris: Fayard, 1982.

Bricker, Victoria. The Indian Christ, the Indian King. Austin: University of Texas Press, 1981.

Bürger, Peter. “The Negation of the Autonomy of Art by the Avant-Garde”. Postmodernism. Thomas Docherty, ed. New York: Columbia, 1993. 237-43.

Cuadra, Pablo Antonio. Torres de Dios. Managua: Academia de la lengua, 1958. El nicaragüense, 4th ed. Managua: El Pez y la Serpiente, 1971. Obra poética completa, 8 vols. San José: Libro Libre, 1984. "On writing in Latin America”. ms. 1986.

Cuadra Downing, Orlando. Antología del árbol nicaragüense. Managua: Pub. Nicaragüenses, s. f.

Delueze, Gilles \& Félix Guattari. Nomadology: The War Machine. New York: Semiotext(e), 1986. 
A Thousand Plateaus. Brian Massumi, trad. Minneapolis: University of Minnesota Press, 1987.

Docherty, Thomas. “Introduction to Part VI”. Postmodernism. Thomas Docherty, ed. New York: Columbia, 1993.

"Postmodernism: an Introduction”. Postmodernism. Thomas Docherty, ed. New York: Columbia, 1993. 1-31.

"Introduction to Part VI". Postmodernism. Thomas Docherty, ed. New York: Columbia, 1993. 319-22.

Dowling, William. Jameson, Althusser, Marx. Ithaca: Cornell University Press, 1984. 108.

Edmondson, Munro (Trad.). The Ancient History of the Itza: The Book of Chilam Balam of Tizimin. Austin: University of Texas Press, 1982.

Felz, Jean Louis. "L'oeuvre de Pablo Antonio Cuadra: recherche d'une culture nicaraguayenne”. Tesis doctoral: Université de Sorbonne Nouvelle (Paris) 1981.

Guardia de Alfaro, Gloria. Estudio sobre el pensamiento poético de Pablo Antonio Cuadra. Madrid: Gredos, 1971.

Habermas, Jürgen. “The Entry into Postmodernism: Nietsche as a Turning Point”. Postmodernism. Thomas Docherty, ed. New York: Columbia, 1993. 51-5.

“Modernity -An Incomplete Project”. Postmodernism. Thomas Docherty, ed. New York: Columbia, 1993. 101-9.

Huyssen, Andreas. "The Search for Tradition: Avant-Garde and Post-Modernism in the 1970s”. Postmodernism. Thomas Docherty, ed. New York: Columbia, 1993. 2213.

Jameson, Fredric. The Prison House of Language. Princeton: Princeton University Press, 1972. Marxism and Form. New York: Princeton University Press, 1974.

The Political Unconscious. Ithaca: Cornell University Press, 1981.

The Ideologies of Power, 2 vols. Minneapolis: University of Minnesota Press, 1988.

"Postmodernism, or The Cultural Logic of Late Capitalism”. Postmodernism. Thomas Docherty, ed. New York: Columbia, 1993. 62-100.

Pring-Mill, Robert. “The Redemption of Reality through Documentary Poetry”. Ernesto Cardenal, Zero Hour and Other Poems. Donald Walsh, trad. y ed. New Directions, 1982, ix-xxi.

Quijano, Aníbal. “Modernity, Identity and Utopia in Latin America”. Boundary 2 XX/3 (Fall 1993): 140-55.

Readings, Bill. Introducing Lyotard. London: Routledge, 1991.

Rojas Jiménez, Oscar. “Poesía de Pablo Antonio Cuadra.” El Universal (Caracas) 17-X1965: 3.

Rothschuh Tablada, Guillermo “Pablo Antonio Cuadra, pionero de una nueva sensibilidad”. La Prensa Literaria 26-V-1974: 2, 5-6.

Tedlock, Dennis (Trad. y ed.). Popol Vuh. New York: Touchstone, 1985. “Introduction”. Popol Vuh. New York: Touchstone, 1985. "Glossary”. Popol Vuh. New York: Touchstone, 1985. 
Tentori, Francesco. “Poesia cattolica in Nicaragua”. L'Osservatore Romano (13-X11953): 3.

Todorov, Tzvetan. Mikhail Bakhtin: The Dialogical Principle. Minneapolis: University of Minnesota Press, 1984.

The Conquest of America, 2nd. ed. Norman: University of Oklahoma Press, 1992. White, Hayden. Metahistory. Baltimore: Johns Hopkins University Press, 1993.

White, Steven F. Poets of Nicaragua. Greensboro: Unicorn, 1982.

Zavala, Xavier. "Entrevista con Pablo Antonio Cuadra”. Felz 1-88. 